\title{
Early childhood teachers' and managers' lived experiences of the COVID-19 pandemic in South Africa
}

\section{Hasina Banu Ebrahim}

Department of Early Childhood Education, College of Education, University of South Africa, Pretoria, South Africa

ebrahhb@unisa.ac.za

https://orcid.org/0000-0002-7896-2598

\section{Colwyn Martin}

Foundation Studies Division, Wits School of Education, University of the Witwatersrand, Johannesburg, South Africa

Colwyn.martin@wits.ac.za

https://orcid.org/0000-0002-1338-9217

\section{Lorayne Excell}

Foundation Studies Division, Wits School of Education, University of the Witwatersrand, Johannesburg, South Africa

lorayne.excell@wits.ac.za

https://orcid.org/0000-0001-6798-5930

(Received: 7 March 2021; accepted: 26 June 2021)

\section{Abstract}

The declaration of COVID-19 as a global pandemic by the World Health Organisation in March 2020 brought many changes to the early childhood sector internationally. The South African response is best understood in the context of an under-developed sector with pre-existing vulnerabilities. In this article, we present a contextual understanding of the lived experiences of early childhood development (ECD) teachers and managers during the lockdown and the opening phases of a risk-adjusted approach. Our use of a phenomenological lens together with systems theory provides a reality check through a focus on lived experiences. Data were produced through an online survey with 28 ECD teachers and managers. We conducted semi-structured interviews with a subset of 8 of these participants. Findings show that disruptions of COVID-19 led to entrenching inequities in service provision and early learning opportunities. These intersecting dimensions have implications for building effective ECD systems.

Keywords: COVID-19, South Africa, early childhood education, teachers, lived experiences, early childhood systems, equity 


\section{Introduction}

The early childhood development (ECD) sector inclusive of early care and learning has experienced the pervasive repercussions of COVID-19. Vulnerable families experienced the discontinuity of early childhood centre-based programmes. In South Africa it is reported that an estimated 1 million children were out of ECD programmes (Wills et al., 2020). This meant compromises in health, nutrition, safety, security, and early learning opportunities in ECD especially for the most marginalised children. Also of concern was the plight of the teachers and managers responsible for offering ECD services and supporting early learning. Taking into account that ECD is a complex sector, in this article we explore teachers' and managers' lived experiences for a more nuanced understanding of experiences in the sector.

Internationally, the perspective of ECD personnel on the impact of COVID-19 has come to the fore through rapid surveys. Of significance to the context of this study, is the Asia-Pacific (AP) and sub-Saharan African (SSA) rapid survey on the situational realities of teachers and managers. (Rothman et al., 2020). A total of 2,040 responses from 34 countries in AP and 1,480 responses from 31 countries in SSA showed that both teachers and managers experienced fundamental shifts in their teaching responsibilities amid concerns related to job security. Only $9 \%$ in AP and 22\% in SSA of teachers in the study were trained in distance learning before the pandemic. Approximately 3\% and 18\% of managers in AP and SSA respectively had training in crisis management. In order to keep learning and communication going, respondents used mobile messengers, social media, and other apps to keep in touch with parents. This was problematic especially for SSA where over $60 \%$ of the respondents did not have effective strategies for continuity of learning. This was attributed to challenges related to data, equipment, training, and geographical isolation of early childhood centres.

In South Africa, it is imperative to understand the plight of the ECD personnel in the light of under-developed systems, under-qualification, and the inequities that implicate mostly black African women. The lack of targeted relief packages, specifically considering the realities of ECD personnel, led to mobilisations from the non-government sector. Two rapid surveys were conducted as baselines for action during the hard lockdown and opening phases. Both surveys contributed to understanding the sustainability of services and learning continuity through distance modes. The first survey (Bridge et al., 2020a) of 3,952 ECD operators in April 2020 showed that $99 \%$ were concerned about the lack of parent fees, while $83 \%$ highlighted their inability to pay full salaries. The re-opening of the centres was also problematic. In August 2020, 4,500 providers participated in a second survey (Bridge et al., $2020 \mathrm{~b}$ ). These findings showed that $68 \%$ found it difficult to re-open their centres. They could not afford the new health and hygiene equipment because of the lack of financial reserves and parent fees especially in the context of disadvantage. Conversely, the ECD teachers and managers in wealthier communities were able to bounce back and provide early learning continuity through digital learning that included parental participation and monitoring (Martin et al., forthcoming). This state of affairs highlights the inequities that are detrimental to those on the margins. 
In this article, we focus on the lived experiences of ECD teachers and managers in order to unpack the impact of the pandemic during the closure and opening phases of the risk-adjusted approach. We were particularly interested in how the new demands, brought on by the pandemic, were negotiated during this time. This study is part of a larger project on ECD capacity building and access. Its particular contribution lies in providing contextual understandings of ECD to inform teacher education. Snapshots of both the advantaged and disadvantaged contexts are presented to show contrasts, synergies, dilemmas, and struggles. The notions of advantaged and disadvantaged are conceptualised in terms of quality programmes and services that include both human and material resources and support (Britto et al., 2011). We believe that tapping into the micro-realities of ECD teachers and managers is imperative if we are to highlight the under-investment in ECD and to advocate for systemsbuilding to better serve the needs of those in this sector.

\section{COVID-19: A compounded crisis for ECD in South Africa}

Since the study is about lived experiences, to gain contextual understandings we present the historical, political, economic, and human resource dimensions to show the overall crisis in ECD. This then flows into a discussion of the compounded crises in the sector in pandemic times.

A historical perspective on ECD in South Africa shows the crisis elements that have impacted negatively on the sector. Ebrahim (2010), in her analysis of three shifts in the early years, showed how the racial divisions created a two-tier system prior to 1994. Stimulating early learning opportunities based on western models of play and school readiness were more available for white children in government-funded pre-primary centres that targeted 3- to 5year-olds. There was limited provision for all other race groups, of which black African children were the most disadvantaged. The practice of custodial care was rampant for children of colour. The government viewed early education as the responsibility of parents. Hence, minimal investments were made for children and their families (Webber, 1978). The best teacher training to support ECD was on offer to white teachers in training colleges while the non-government organisations (NGOs) took responsibility for early childhood teacher training through donor funding (Department of Education, 2001).

The democratic political turn in 1994 resulted in greater efforts towards equity, access, and redress. The concept of preschool education gave way to ECD that focuses on holistic child development (Department of Education, 1995) including early learning for children from birth to 9 years of age. The Pre-Grade R early childhood sector catering for children from birth to 4 years of age continues to pose challenges. The National Integrated ECD (NIECD) Policy (Department of Social Development and UNICEF 2015) has the ambitious aim of transforming ECD service delivery to address the gap in universally available equitable services. From an economic perspective, there is a mismatch between the funding strategies and infrastructure to support the aim of the NIECD. The NGOs sometimes partner with government and continue to deliver ECD programmes with limited funding. In the absence of adequate subsidies to community-based early learning sites, most rely on parent fees. While 
this is affordable for those in well-resourced households, it is problematic for families living in poverty. The mushrooming of private providers with business orientations and unregistered sites continues to be a feature. The latter are difficult to trace since they operate outside of the regulatory framework of the Children's Act 38 (Republic of South Africa, 2005) and the service guidelines (Department of Social Development - City of Cape Town, 2015).

From a human resource perspective, ECD fails to attract high quality personnel although many are attracted to the Foundation Phase. This is because of the lack of status and the under-development of a robust system to professionalise the field. Also of concern is the under-qualification of both teachers and managers in the sector. The ECD audit (Department of Social Development and Economic Policy Research Unit, 2014) showed that the majority of teachers (90\%) were black women. Personnel qualifications were lacking. In registered ECD sites, approximately $35 \%$ of the managers and $40 \%$ of the teachers had not completed Grade 12 . Only $43 \%$ of managers and $30 \%$ of teachers had ECD certificates at any level. Specialisation in ECD is problematic: $37 \%$ of managers had no ECD specialisation and 55\% of the teachers did not hold formal qualifications.

The discussion on the historical, political, economic, and human resource dimensions shows vulnerabilities that led to a compounded crisis during the pandemic. Research continues to highlight the challenges that implicate teachers and managers such as those involved in digital learning, the plight of at-risk children, and the need for urgent government action. For learning continuity through digital modes, a variety of resources was developed for young children. Ebrahim (2020) noted that the effectiveness of these resources as pedagogical support must be viewed through the lens of teacher capacity for offering psychosocial support, digital skills, assessment of learning loss, as well as the ability to work with at-risk children at a distance and engage caregivers as partners. Martin et al., (forthcoming) have contended that there are struggles at the frontline as teachers and managers battle with the problems of digital learning, contestations regarding parent participation, and stress. Their findings show that those in the disadvantaged context continue to be more vulnerable than their advantaged peers who had better infrastructure for learning continuity prior to the pandemic. The study conducted by Koen et al. (2021) revealed the impact of the pandemic on the holistic development of children at-risk in rural ECD centres. Their findings showed the need for resources, psychosocial support, and guidelines to address the needs of at-risk children. In addition, there is an urgent need to build teacher resilience and pay attention to building resilient systems that will support them (Martin et al., forthcoming). Willis et al., (2020) have rightfully pointed out the need for urgent government action to ensure equity, sector survival, and sustainability and, we would add, human resource development. Advocacy campaigns by organisations such as Real Reform have drawn attention to different avenues for action and continue to contest government responsiveness to realities facing the sector. This small-scale study offers insights into issues that add to the call to action for ECD. 


\section{Theoretical framework}

This study is informed by phenomenology and systems thinking. Lived experience is understood in the context of the philosophy and methodology of phenomenology. Streubert and Carpenter (1995) viewed phenomenology as a science. Vagle (2014, pp. 11-12) expanded its definition to include "an encounter, a way of living and a craft" and we found this definition more appropriate to this article since it allowed for a stronger interpretive dimension of human experience to come to the fore.

The concept of being-in-the-world as foundational to human existence is relevant to this study. Heidegger (1927/2011) explained that being-in is more about the formal side of an existential expression. For him, Dasein refers to the ways in which being is peculiar to human beings in that while we are ultimately alone our being alive is related to the existence of others. Dasein, or being-in-the-world, is considered to be an essential state. In this article, being-in-the-world is viewed as connectedness in that the practice of the ECD personnel is seen to be interconnected to the broader conditions that make certain things possible. The lived experiences of the ECD personnel illuminate realities in pandemic times during which inequities and systemic under-development have shown their negative impacts.

The frontline actions presented to us through the teachers' and managers' experiences are linked to macro-realities at systems level. What the teachers and managers reported is not just about what was happening to them in a narrow sense. Rather, in line with the notion of Dasein, we view these as partial results of a variety of complex elements at play within an ECD system. Systems theory views all phenomena (including ECD) as having relationships among many parts that together make up a system (Lazlo, 1996). The parts do not have meaning on their own, but they interact with other parts, and this makes it possible to identify patterns that provide insights into complexities and help to unravel the nuances. In the case of ECD, the science, policies, and practice can be viewed as parts of a system that should work together when programmes in education, social development, and health are integrated for service provision to support holistic child development. Comprehensive programmes together with supportive institutional elements (governance, funding, human resources, quality controls, and family engagements) are crucial to shaping the conditions for quality ECD.

Kagan et al. (2016), in their exploration of systems theory and thinking in specifically early childhood education (ECE), contended that in order to achieve successful child and family outcomes it is critical to focus on equity, quality, and sustainability as dimensions of effective ECE systems. Equity is about resource allocation spanning a period of time to allow for different sectors, different geographical locations, and populations of different age groups to access opportunities to address the deprivations experienced (World Bank, 2006). The poor and the disadvantaged require more targeted resources to address their unmet needs. As noted previously, quality refers to attributes of ECD programmes, the service provider, and the staff (Kagan et al., 2016). The main concern is about how the human resources support families and their children. Sustainability refers to the financial, political, and contextual aspects that 
assist systems to function well over a period of time and adapt to changes taking place in the political, economic, and environmental arenas of influence (Kagan et al., 2016).

In this article, systems theory and the three-pronged concerns for effective ECD systems allows us to use the teachers' and managers' lived experiences in their micro-realities to broaden discussion on the conditions that have shaped ECD during pandemic times.

\section{Methodology}

Following Yin (2014), the phenomenological lens made the qualitative approach an obvious choice. Purposive sampling was suitable for the study. Participants were drawn from the greater Johannesburg metropolitan area that included advantaged as well as disadvantaged contexts situated in suburban, township, and informal settlements. Selection criteria included centre-based teachers and managers who facilitated care and early learning for children between the ages of 1 and 5 years. Participants had to have a recognised ECD qualification that ranged from the minimum Level 4 ECD qualification to a Bachelor of Education degree. ${ }^{1}$ It was assumed that these participants had the basic competence to engage with early learning and care issues.

Data collection proved to be challenging since the traditional face-to-face interview could not be implemented because of COVID-19 restrictions. Distance-oriented approaches (Tuttas, 2015) enabled us to address some of these limitations. Woodyatt et al. (2016) noted that online platforms allow for participants to generate shorter substantive responses in a safe and less threatening environment. We used an online survey through Google forms and video conferencing through Zoom and WhatsApp interviews.

The online survey was conducted first. A structured questionnaire was sent to 28 participants who had previously given their written consent. The surveys provided rich data on how ECD teachers and managers made meaning of their experiences and material practices (see Braun et al., 2020). We made a methodological choice to "treat, and work with the data as one cohesive dataset, coding and developing analytic patterns across the entire dataset" (Braun et al., 2020, p. 10). This initial interpretive analysis allowed for preliminary analytical interests and thoughts to come to the fore. Thereafter, we purposively selected eight participants for individual online semi-structured interviews. Three participants opted for a Zoom interview and five chose a WhatsApp voice call.

The choice of eight participants was based on their responses to the survey that gave initial insights into their challenges along with their responsiveness to these. The semi-structured interviews enabled further clarification and a deepening and extension of their responses in the survey. The semi-structured interview schedule was comprised of broad themes that had questions about teaching and learning, service provision support, parental engagement, their

1 A level 4 ECD qualification is recognised as an entry level qualification into the ECD field (South African Qualifications Authority, 2007). 
feelings during the COVID-19 pandemic, along with a request for suggestions on the way forward for handling uncertain and complex situations.

We adapted Braun and Clarke's (2006) six phases of thematic analysis. Phase 1 required that we familiarise ourselves with the different data sets. In order to become more familiar with the data, we embarked on preliminary acts for "rich interpretation" (Lapadat \& Lindsay, 1999 , p. 69). We transcribed participants' responses verbatim to ensure that actual utterances informed our thinking. In Phase 2, we identified initial codes and organised data into meaningful groups informed by the interview questions. Phase 3 was comprised of searching for codes across both data sets and identifying probable themes. In Phase 4, we revised the themes (see Patton, 1990) and in Phase 5 we consolidated these into five themes. In this article we report on two of these. Our reasons for this choice were two-fold: first, we were informed by the aim of this article which was to tap into the lived experiences of ECD teachers and managers; and second, we were constrained by the space limits of this article. In Phase 6, we made particular choices about the arrangement of the themes to support our arguments.

We recognised that many ECD teachers struggle with online communication. We thus made additional efforts to ensure that all participants understood what we were asking and also made sure that they felt comfortable enough to clarify any uncertainties. We were fortunate that all our participants were comfortable with responding in English.

The ethics application was obtained for a larger project on capacity building and access programme support at UNISA. ${ }^{2}$ The study contributes to contextual understandings that will assist in capacity building efforts for teacher education (see Martin et al., forthcoming). The online survey included consent forms and consent was renegotiated for the semi-structured interviews. Participants were also assured of confidentiality and that their participation was voluntary.

\section{Findings}

We discuss the findings in two themes related to service provision support and early learning.

\section{Service provision support: Continuities and discontinuities}

Service provision support must be understood within the broader context of COVID-19 in an emerging public sector riddled with inequities. Researchers have noted that the pandemic has highlighted structural inequalities and "numerous fault lines" in the ECD sector (Haffajee \& Levine, 2020 p. 1). Despite the Minister of Social Development (DoSD) having praised "sector-wide co-ordination and collaboration" support from DoSD in pandemic times, in many of the provinces, this has been "invisible at best and obstructive at worst" (Vorster, 2020, p. 1).

2 Unisa stands for the University of South Africa, a distance Higher Education Institution. 
The above can be understood in terms of weak systems, inadequate policy implementation, and a lack of adequate investment in a field experiencing existing inequities. For example, Participants 1, 3, 6, 9, and 13 said that they had not received a salary because centres had shut down and no monies had been received from parents. Participant 10 supported these claims and added that "there was no support at all from any NGOs or government." This lack of support was echoed by Participants 19, 23, and 25. Participants 21 and 22 commented that "everything stopped." Only Participants 8 and 23 mentioned that they had received some form of relief such as an Unemployment Insurance Fund (UIF) pay-out. Giese (2020) noted that the registration of the ECD workforce with the UIF is rare, and this makes it difficult for them to access any financial support when job losses occur. However, participants who worked in advantaged contexts continued to receive their full salary. Participant 5 said, "No salaries were cut as we continued to work online" while for Participant 18, "Funds were still received from families and I was able to draw my salary and pay my employee."

COVID-19 also exposed vulnerabilities in the social, digital, and economic ECD systems that, in turn, impacted on the kinds of provision that were offered to children and parents. Advantaged ECD centres had multiple levels of support. These included financial and digital resources and strong leadership to support the shift to online teaching and learning. The teachers and children in the advantaged contexts were well equipped with the necessary digital infrastructure, digital devices, and human resources to cope with online learning. Furthermore, strong leadership at the centres revealed a sustainable approach to change in that focused attention was brought to people, systems, and processes that opened possibilities and continuities for learning (see Douglass, 2017). Participant 5 said,

We received support from the academic team at head office and the principal . . . they organised training for online teaching, and we were provided with learning guidelines so that we were all teaching the same things, across the board.

Additionally, the strong leadership ensured that teachers were supported in adjusting to what became known as the new normal. As Participant 5 commented, "She [the principal] organised online learning training sessions for us and made sure that we had all the resources that we needed to plan and implement our online programme."

At the centre where Participant 2 taught, the principal was responsive to issues at both the micro- and macro-level, hence service provisioning was made possible. As she explained,

She set up a Covid team who explained all the protocols that had to be followed ... the team helped us to set up our online learning lessons ... helped with our planning for online teaching ... they helped us to continue with our teaching.

For Participant 18, support came from "an ECD group that we formed with teachers from other centres because we couldn't really rely on government." This statement highlights the non-responsiveness of government and shows how this participant had to build trusting and reciprocal relationships with peers in the community. This participant went on to say, "Because we couldn't really rely on government, we looked for an approach that would work 
best for us . . this local community communication and networking became an important source of support."

The lack of support from government had a greater impact on ECD centres in vulnerable communities. While the advantaged sector was able to absorb the shocks created by the pandemic, many of the participants in disadvantaged contexts struggled to respond to the new demands brought about by it. They had to access outside support to ensure continuity of service provisioning. For example, Participant 24 received support from the training centre where she was studying towards an improved ECD qualification. She said, "They trained me on the different COVID protocols that we had to put in place, and they also gave me data to update my principal with the COVID protocols." Her principal also "got support from a nonprofit organisation ... [that] gave us sanitisers [and] learning materials and trained us on how to follow the protocols." She talked further about the support they received from "a nurse from the community who organised sanitisers for us and told of us about the meetings about COVID-19 that [were] held in the community." Participant 1 received support from a social worker in the community who "checked if we were compliant; they advised us about some changes we had to make. We were issued with a compliance certificate." However, Participant 24 commented that she and others experienced difficulties in having support take effect. She said,

But it was hard because we had to wait ... wait for the donations, wait for the information, we had to wait for parents to pay fees, we had to wait for everything, and this was very bad. We wanted to open in September, but we had to wait for social development to come and check the centre to see if were following protocols.

Unlike some healthcare services and education in schooling, ECD services are poorly financed by the government. They rely largely on parent fees and, for some, a small government subsidy to cover daily running costs and salaries of staff. Participant 24 said, "Because most of the children were not coming to school, parents didn't pay fees, the principal had to let some of the teachers go." For Participant 10 (the principal), the lockdown not only removed the small government subsidy that she received from DoSD, but it also increased expenses. She explained,

I had to use my own money to buy [personal protective equipment] PPE and COVID19 learning materials for children and [their] parents. I had to buy masks, charts, sanitisers, and plastic to cover the children's tables . . . it was very hard.

According to the South African Childcare Association (2020), subsidy distributions are problematic in COVID-19 times; they have been withheld.

Because of a lack of consistent government support, some of the ECD centres procured support from the NGO sector. Participant 25 said that they received support from the South African Childcare Forum in the form of "workshops with not only COVID related [material] but also in other fields of teaching and learning. Our principal also organised training for online teaching." Participant 1 attended “online COVID-19 training by X T Early Care 
Foundation ... We were given more knowledge and better understanding about the virus and how to prepare our centre for re-opening, e.g., fumigation [and] social distancing."

Participant 25 mentioned that the kind of support they received from the NGO centred around "COVID-19 protocols, how to get the centre COVID compliant and knowledge around preparing for re-opening of the centre."

Participants in more advantaged contexts mentioned that while they did not receive adequate support from government, parents stepped in to effect the changes that had to be made for the continuity of service provision. ECD centres in advantaged contexts already had basic channels of communication and support in place. The teachers procured support from parents via WhatsApp group chats, email, and newsletters. Participant 2 commented, "Parents were grateful for the help with their children's learning during lockdown and they were always willing to help . . . but then we have had their support." Participant 18 said that "parents continued to pay normal school fees, and this allowed for the running of the centre." Participant 25 also formed a "WhatsApp group chat with parents and this made it easier to communicate with them and get their support."

Equally, in disadvantaged contexts, teachers made attempts to garner support from parents via WhatsApp and messaging. In Participant 24's context, parents wanted continuity of learning. As she indicated, they contributed financial and physical support.

Most of the support was from the parents especially financially because they wanted to make sure that their children were safe. They bought health and safety equipment like face shields for the children and equipment like PPE, cleaning materials, and table dividers for the children ... They also came to check that we had everything in place before we opened the centre. They made sure that we were social distancing and doing the correct procedures at the entrance of the centre.

\section{Early learning: Continuities, discontinuities, and adaptations}

It was evident in the study that early learning was an arena of many uncertainties. Even though $80 \%$ of centres have partially re-opened since the easing of the hard lockdown, children attending these centres appeared to have access to limited early learning opportunities. Only $15 \%$ of the centres were able to adapt their programmes effectively to offer meaningful learning opportunities to children through varied modes of delivery. Centres that were unable to access sufficient resources to re-open constituted 5\%.

Meaningful interactions with parents and their children ceased during the initial phase of hard lockdown when centres closed. Of the participants, $68 \%$ felt powerless and helpless. Participant 24 said, "I have found this lockdown very hard. It changed my life in so many ways because I had to worry about my home life and my teaching job . . . I felt helpless." Participant 10 commented, "I felt overwhelmed and helpless thinking that no one cares about ECD in South Africa." Others, once the initial paralysis had worn off, began to make attempts to contact parents to promote some continuity of ECD provision and $76 \%$ of participants were able to keep in contact with their colleagues and parents via WhatsApp 
groups but they were not able to adapt their programme to offer some alternative mode of learning to the children. The communication channels that they established proved to be invaluable when their centres re-opened. In centres where staff had minimal or no contact with parents during the hard lockdown it became difficult to plan for re-opening.

Only $15 \%$ of participants (predominantly those from the more advantaged contexts) were able to access additional support and implement alternative possibilities for learning continuity; they replaced contact teaching with some form of online teaching either through Zoom, Microsoft Teams meetings, or WhatsApp. Participant 18 sent voice messages that parents could replay to their children. This enabled her to connect with the children and it enhanced the learning relationship. She said, "I think it really helped." Participant 25 made use of online video lessons so that children could connect with her visually and both parents and children found this stimulating. This relational connectedness helped to further the early learning of children then and later supported both the planning to re-open as well as the actual re-opening of the centre. In this way participants were able to build a sense of stability and relational connectedness and enhance learning, all of which facilitated the planning for and re-opening of their centres.

Adapting to an online mode of delivery proved challenging. Participants 2, 5, 18, and 25 maintained that parental participation was identified as an essential element to ensure the successful continuity of early learning, especially with the younger children. Participants found it difficult to decide which content to share online and the type of activities to do with the children to keep them focused and attentive during screen time. Participants 2 and 5 were given outcomes by the academic head of their institution and were then required to "develop lessons around these outcomes." A supportive resource for these participants was a Choice Box that was shared with parents. This was comprised of extension activities that they could do with their children. Participant 18 said that she supplemented the online teaching with activity packs that were sent to all children. Where parents were not able to fetch these packs, she dropped them off at the children's homes. These strategies also enabled parents to work with their children at times convenient for the family and so promoted the extension of the learning programme. Where there was continuity of teaching and learning all participants acknowledged that the learning space changed in that they had to adapt their homes into classrooms. As Participant 25 noted, "It's not easy to turn your house into a classroom by night but we tried."

Participant 18 mentioned that through online teaching she and the parents "[had] become closer." Parents, for example, witnessed teaching in real-time and the shift that happened from teachers and children interacting to teachers, children, and parents doing so. However, for Participant 5, "Parent participation became a barrier rather than an enabler of children's learning as often the parents did the work for their children." Participants 5 and 18 noted that not all parents were willing or able to support their children's learning. Some had time constraints and for others the learning needs of older siblings were seen as the priority. A further challenge to the successful implementation of online learning included connectivity 
issues and ensuring the availability of sufficient data for both teachers and parents to engage online.

As already mentioned, most of the teachers were not able to make a successful shift from face-to-face to online learning. Even when centres re-opened, participants found it very challenging. Participant 24 acknowledged that

it was very difficult, learning became slow, and children were not coming every day. I couldn't do the same things that I did before because I was not teaching my same group. I found that learning was not fun like before because I had other groups that I was teaching.

She found it harder to communicate with both parents and children and, as a result, there was a discontinuity of conventional learning especially in relation to the delivery of the daily programme. However, some participants $(1,12$, and 21$)$ made attempts to continue with the daily programme. They sang songs, recited rhymes, and read stories. Even in difficult circumstances there was a realisation from some teachers that interactive, concrete-based learning was an important early learning approach to ensure learning continuity.

But for the majority the emphasis was on teaching and implementing health protocols and ensuring that children and parents were compliant with the protocols. The daily programme revolved around teaching and reinforcing health protocols to the exclusion of any other learning goals. Participant 10 mentioned,

I am teaching my kids to wash their hands more often and regularly, for example after using the toilet, before eating and after eating. They must always cover their mouth and nose with their elbows while coughing instead of using their hands. I have taught them social distancing between each other and not to share anything with others before it is sanitised by the teacher.

This transcript highlights how changes in the daily routines became the focus of alterations made to the learning programme. Participants 1, 10, 15, 21, and 23 ensured that there was an increase in hand washing and sanitizing to prevent the spread of the virus among the children. The content change was to educate the children about COVID-19 protocols. This included explanations to children of why they could not play in groups. Participants appeared to show a blind acceptance of these health protocols with an overemphasis on the teaching and/or sharing of them with both the children and the parents. Peer and collaborative learning were also inhibited because of the strict adherence to social distancing. Participant 1 also mentioned the reluctance of staff to let children play either outdoors or with their toys.

This strict adherence to implementing COVID-19 protocols was driven by concerns about the children's safety as well as the realisation that if teachers were not cautious there would be a lack of demand for the ECD service as well as the threat of closure if the centres were noncompliant. These challenges were fuelled by a lack of adequate learning materials and limited financial support to buy data and PPE. 
Participants found it difficult to adapt to the COVID-19 requirements and offer a successful and stimulating early learning programme at the same time. Consequently, the demand for a quality programme decreased. This was further exacerbated by parents being scared to send their children to the ECD centres along with massive job losses which meant that out-ofhome childcare became unaffordable. Some parents, according to Participants 1,10, and 24 also contracted COVID-19 and were therefore unable to attend to childcare. In addition, parents acknowledged that they had competing priorities. For example, Participant 25 recalled a parent saying, "Older children need more attention than the younger children." Participant 18 noted that a parent said, "I don't have the time to work with my youngest child."

\section{Discussion}

The lived experiences of the teachers and managers in the context of the pandemic show how the pre-existing crisis, related to the lack of a government led ECD system, precipitated vulnerabilities. This raises concerns for equity, quality, and sustainability in ECD. Kirby (2020), in her discussion of the disruptions of the pandemic at the frontline in education, showed how affluent settings were able to migrate to online options with support from parents where possible. She argued that poor countries and communities that were fragile from the beginning, had vastly different experiences. Their struggles related to survival that exposed the deficiencies in weak systems. Yoshikawa et al. (2020) have called for equity and sustainability to be high on the agenda of governments and NGO partners not just for the current generation but for future ones, too. Shared responsibilities and co-ordinated actions are viewed as central to buffer the current crisis and future ones.

It is important to read the findings of this study in the context described above. It shows the relative ease with which personnel working in the advantaged contexts were able to migrate to the online environment, earn normal salaries, enable professional support, encourage parental participation, and mobilise leadership. These actions are hallmarks of an assertive community that uses its resources and infrastructure to secure advantage. For them, government support would be a nice-to-have but is not essential since they are able to hold their own in functional market-based models.

However, in the disadvantaged contexts the picture is far from promising. ECD centres are staffed by an overwhelming majority of black African women, and some were using their own money to keep their centres open. For these centres, parent fees and a government subsidy are a must-have for sustaining their services. This study further highlights the widening of the gap between the haves and the have-nots which was, of course, a major issue before the pandemic. Cooper (2021) in her analysis of provision across income quintiles, showed that children from affluent families are more likely to be enrolled in an early childhood programme. Using Statistics SA data for 2015 she noted that only 58\% of 3- to 5year-olds in the poorest quintile, in contrast to $80 \%$ in the wealthiest quintile, had access to early childhood programmes. White children still continue to have more access than any other race group. This means that children growing up in vulnerable circumstances are less 
likely to enter early childhood programmes while their privileged counterparts flourish with their basic needs already in place.

The concerns for quality intersect with concerns for equitable access. The study shows that the pandemic put in place make-shift measures that favoured those in advantaged contexts to keep early learning going. In both contexts, the teachers were responding to parental demands or the lack thereof. There were strategies to encourage parental participation through a variety of means. The lack of strong government support to enable quality was largely absent. Hickman and Matlhape (2021) stated that where providers position themselves as entrepreneurs with or without limited subsidy support, the government has to assert its role in implementing ECD as a public good with attention to quality. Kagan et al., (2016) argue that attaining quality is difficult and we would argue that this is even more so in compounded crisis times. To obviate an ad-hoc approach, attention should be given to seven intersecting production variables: governance; finance; programme quality standards with attention to transitions, assessment data and accountability; human capacity development; family and community engagement; and linkages with external influencers. These variables have received uneven attention. Silo functioning has disabled advancement for developing effective systems for sustainable ECD.

Despite systemic weakness and the absence of a robust government response in times of compounded crisis, this study shows resilience amid the fragile circumstances in which the ECD teachers and managers operate. They were able to access support from online resources, NGOs, parents, and members of the community to keep early learning going. They were forced to position themselves as thinking teachers who had to re-organise their daily programmes to accommodate new requirements for health and safety. The challenges experienced caused stress and anxiety and this does indeed draw attention to the kind of teacher who is needed for supporting ECD in uncertain times. The quest to find strategies to address the challenges of the pandemic and to find new ways of doing and thinking is promising for building resilience in the ECD personnel. The way in which the teachers accessed support also showed how social capital can circulate to offer support. This is a promising starting point for sustainable ECD. Blom (2021) argues that forums in which a hub of ECD centres represent a community are valuable in forging connections. Communities, governments, NGOs, and training organisations must come together to support the scaling up of ECD services for sustainability.

\section{Concluding remarks}

Through an analysis of the lived experiences of ECD teachers and managers in pandemic times, we have shown the struggles, tensions, and affordances of practices that characterised the ECD sector in the closing and re-opening of the centres. Through a bottom-up exploration of the state of play in ECD in compounded crisis times, our findings show the repercussions of a weak systems response to ECD. Of major concern are the inequities related to early learning and development opportunities for young children and the basic conditions of service support for their teachers and managers in the disadvantaged contexts. These are 
important arenas for consideration in a government led ECD context that connects with capital from civil society as we head towards universal access in the early years. Therefore, it is imperative that a whole society and whole government approach as Twala (2021) has pointed out, is set in motion. This must begin with a clear understanding of the landscape of ECD with its interventions and its implications for effective systems building in the new normal. The collective effort among partners has the potential to work from a shared vision and reduce polarisations that are counter-productive to achieving sustainable ECD within a rights-based framework. The study is limited to a small sample in Gauteng. Future research on ECD systems building in pandemic and post-pandemic times could include large-scale studies directed towards producing evidence to harmonise systems in a fragmented sector.

\section{References}

Blom, J. (2021). The role ECD forums play in strengthening ECD centres. In E. Atmore, M. Ashley-Cooper, \& L. van Niekerk (Eds.), Thought leaders on early childhood development in South Africa: A collection of thought-provoking essays (pp. 52-55). Centre for Early Childhood Development.

Bridge, Illifa Labantwana, the Nelson Mandela Foundation, National ECD Alliance, SmartStart, \& SA Congress for ECD. (2020a). The plight of the ECD workforce: An urgent call for relief in the wake of Covid-19.

https://www.google.com/search?q=The+plight+of+the+ECD+workforce\&oq=The+pl ight+of + the $+E C D+$ workforce $\&$ aqs $=$ chrome. $69 \mathrm{i} 57 \mathrm{j} 69 \mathrm{i} 6413.9145 \mathrm{j} 0 \mathrm{j} 7 \&$ sourceid=chrom e\&ie $=U T F-8$

Bridge, Illifa Labantwana, National ECD Alliance, SmartStart, \& SA Congress for ECD. (2020b). Second survey assessing the impact of Covid on ECD. https://doi.org/ilifalabantwana.co.za/wp-content/uploads/2020/10/157-Ilifa-COVIDSurvey-Infographic_v03.pdf

Braun, V., \& Clarke, V. (2006) Using thematic analysis in psychology. Qualitative Research in Psychology, 3(2), 77-101. ISSN 1478-0887

Braun, V., Clarke, V., Boulton, E., Davey, L., \& McEvoy, C. (2020). The online survey as a qualitative research tool. International Journal of Social Research Methodology. http://doi.org/10.1080/13645579.2020.1805550

Britto, P. R., Yoshikawa, H., \& Boller, K. (2011). Quality of early childhood development programs in global contexts: Rationale for investment, conceptual framework and implications for equity and commentaries. Social Policy Report, 25(2), 1-31.

Cooper, A. (2021). The inequality of access to early childhood development programmes in South Africa. In E. Atmore, M. Ashley-Cooper \& L. van Niekerk (Eds.), Thought leaders on early childhood development in South Africa: A collection of thoughtprovoking essays (pp. 24-34). Centre for Early Childhood Development. 
Department of Education. (1995). White paper on education and training. Government Printer.

Department of Education. (2001). The nationwide audit of ECD provisioning in South Africa. Government Printer.

Department of Social Development \& Economic Policy Research Institute (EPRI). (2014). Audit of early childhood development (ECD) centres: National report. Government Printer.

Department of Social Development \& UNICEF. (2015). National integrated early childhood development policy. Department of Social Development.

Department of Social Development, City of Cape Town. (2015). Investing in early childhood development to build a caring city.

https://resource.capetown.gov.za/documentcentre/Documents/Graphics\%20and\%20ed ucational\%20material/CCT_ECD_guide.pdf

Douglass, A. (2017). Leading for change in early care and education: Cultivating leadership from within. Teachers College Press.

Ebrahim, H. B. (2010). Mapping historical shifts in early care and education in South Africa. Journal of Education, 48, 119-135.

Ebrahim, H. B. (2020). Digital learning in early childhood education in Africa: Problems, effects, solutions [Distance learning in early grade levels webinar]. Zoom platform IICBA-UNESCO.

Giese, S. (2020, October 1). The collapse of early childhood development is a constitutional crisis - urgent action is needed now. Daily Maverick. https://www.dailymaverick.co.za

Haffajee, S., \& Levine, D. T. (2020). 'When will I be free': Lessons from Covid 19 for child protection in South Africa. Child Abuse \& Neglect, 110,104715. https://pubmed.ncbi.nlm.nih.gov/33071025/

Heidegger, M. (2011). Being and Time (J. Macquarrie, \& Robinson, Trans.). Harper \& Row. (Original work published 1927)

Hickman, R., \& Matlhape, G. (2021). Registering and funding home-based ECD programmes: Understanding the legal, policy, social and economic case. In E. Atmore, M. Ashley-Cooper \& L. van Niekerk. Thought leaders on early childhood development in South Africa: A collection of thought-provoking essays (pp. 56-66). Centre for Early Childhood Development. 
Kagan, S. L., Araujo, M. C., Jaimovich, A., \& Aguayo, Y. C. (2016). Understanding systems theory and thinking: Early childhood education in Latin America and the Caribbean. In A. Farrell, S. L. Kagan \& E. M. Tisdall (Eds.), The Sage handbook of early childhood research (pp. 165-184). Sage.

Kirby, J. (2020). Education disrupted: Stories from the frontline of Covid-19's education crisis. WISE. https://www.wise-qatar.org/education-disrupted-stories-from-thefrontline-of-covid-19s-education-crisis.

Koen, M., Neethling, M., \& Taylor, B. (2021). The impact of COVID-19 on the holistic development of young South African at-risk children in three early childhood care and education centres in a rural area. Perspectives in Education, 39(1), 138-156.

Lapadat, J. C., \& Lindsay, A. C. (1999). Transcription in research and practice: From standardization of technique to interpretive positionings. Qualitative Inquiry, 5(1), 64-86.

Lazlo, E. (1996). The systems view of the worlds. A holistic vision of our time. Hampton Press.

Martin, C. D., Ebrahim, H. B., \& Excell, L. (forthcoming). Struggles at the frontline in pandemic times: Time to reimagine early childhood development in South Africa. In L. Henderson, H. B. Ebrahim \& K. Bussey (Eds.), Responding and speaking back to the global pandemic. Challenges and opportunities. Routledge.

Patton, M. Q. (1990). Qualitative evaluation and research methods (2nd ed.). Sage.

Republic of South Africa (RSA) (2010, April 1). The Children's Act 38 of 2005.

Consolidated Regulations pertaining to the Children's Act, 2005. Government Notice No R261. Government Gazette, No. 33076.

Rothman, S., Hillman, K., Thompson, J., \& Lay, D. (2020). Analysis of data generated from the regional early childhood education personnel surveys on the impact of and responses to COVID-19 in Asia Pacific and Sub-Saharan Africa. UNESCO/ACER.

South African Childcare Association. (2020, October 20). [Press release.] https://sachildcare.net/wp-content/uploads/2020/10/Press-Release-21-October2020.pdf.

South African Qualification Authority (SAQA). (2007). The uptake and impact of qualifications and unit standards in the subfield: Early childhood development. SAQA.

Streubert, H. J., \& Carpenter, D. R. (1995). Qualitative research in nursing: Advancing the humanistic imperative. Lippincott. 
Tuttas, C. A. (2015). Lessons learned using web conference technology for online focus group interviews. Qualitative Health Research, 25(1),122-133.

Twala, Z. (2021). A great chance to accelerate early learning development for children in South Africa. In E. Atmore, M. Ashley-Cooper \& L. van Niekerk (Eds.), Thought leaders on early childhood development in South Africa: A collection of thoughtprovoking essays (pp 4-9). Centre for Early Childhood Development.

Vagle, M. D. (2014). Crafting phenomenological research. Left Coast Press.

Vorster, R. W. (2020, August 20). Government pushes Early Childhood Development centres and welfare organisations to the brink [Opinion piece]. Daily Maverick. https://www.dailymaverick.co.za

Webber, V. K. (1978). An outline of the development of preschool children in South Africa: 1930-1977. South African Association for Early Childhood Education.

Wills, G., Kotzé, J., \& Kika-Mistry, J. (2020). A sector hanging in the balance: Early childhood development and lockdown in South Africa. RISE Working Paper Series. 20/055.https://doi.org/10.35489/BSG-RISE-WP_2020/055.

World Bank (2006). World development report 2006: Equity and development. The World Bank.

Woodyatt, C., Finneran, C. A., \& Stephenson, R. (2016). In-person versus online focus group discussions: A comparative analysis of data quality. Qualitative Health Research, 26(6),741-749.

Yin, R. K. (2014). Case study research design and methods (5th ed.). Sage.

Yoshikawa, H., Wuermli, A. J, Britto, P. R., Dreyer, B., Leckman, J. F., Lye, S. J., Ponguta, L.A., Richter, L., \& Stein, A. (2020). Effects of the global coronavirus disease-2019 pandemic on early childhood development: Short- and long-term risks and mitigating program and policy actions. The Journal of Pediatrics, 22(3), 189-193. 